\title{
ИНОКУЛЬТУРНЫЕ АНТРОПОНИМЫ В ПРОЦЕССЕ РУССКО-ПОЛЬСКОГО ПЕРЕВОДА В КОНТЕКСТЕ ИНДИВИДУАЛЬНОГО ПЕРЕВОДЧЕСКОГО ПОДХОДА
}

\author{
PERSONAL NAMES FROM FOREIGN CULTURES IN RUSSIAN-POLISH \\ TRANSFER IN THE CONTEXT OF THE INDIVIDUAL \\ TRANSLATOR'S APPROACH
}

\author{
JOLANTA JÓŹWIAK
}

\begin{abstract}
The paper deals with the problem of rendering personal names from foreign cultures into Russian and Polish. An individual approach is required from the translator in every separate case because of the distinctions in the perception of these culturally-determined elements. There are many situations when the modification of standard translation procedures is required, particularly when the unit is used in an unusual function. Irrespective of the orientation to form or meaning, the reactions of readers and potential associations are the most important.
\end{abstract}

Jolanta Jóźwiak, Uniwersytet Kazimierza Wielkiego, Bydgoszcz - Polska, jjozwiak@poczta.onet.pl

В эпоху диалога культур и установки на сохранение культурной специфики могло бы показаться очевидным использование переводчиками экзотирующих техник для передачи культурно обусловленных элементов исходного текста. Однако, рассматривая результаты переводческих решений, следует задать вопрос: выполняют ли подобранные переводчиками единицы функции, соответствующие интенции автора?

Настоящие рассуждения будут посвящены инокультурным персоналиям - одному из видов появляющихся в русско-польском переводе единиц, которые не принадлежат ни к культурному кругу оригинала, ни перевода. В польской переводческой литературе для их определения употребляется термин элементы третьей культуры, предложенный Д. Урбанэк [Urbanek 2004: 160]. Как утверждает исследовательница, такого типа единицы совпадают с так называемыми носителями чуждости Р. Левицкого, т. е. элементами, обладающими способностью вызывать ощущение чуждости у читателей переводческого варианта текста [Lewicki 2000: 45].

Рекомендации (теоретического и практического характера) по вопросам введения имен собственных, в том числе и персоналий, в рус- 
скоязычный текст даются, например, в работах С. Влахова, С. Флорина, В.С. Виноградова, Н.К. Гарбовского, И.С. Алексеевой и прежде всего в монографии Д.И. Ермоловича, позволяя переводчику сориентироваться, почему встречаемые им слова имеют такой, а не другой облик.

Однако, как известно, правила записи персоналий чужого, по отношению к оригиналу и переводу, происхождения в польском языке существенно отличаются от правил, соблюдаемых в русском языке. По общим рекомендациям польский переводчик должен восстановить изначальный облик таких единиц, т. е. вернуться к оригинальной записи. Однако реализация постулата намного сложнее, чем представляется вначале, и, следовательно, вызывает потребность индивидуального переводческого подхода в отдельных случаях. Поэтому стоит посмотреть на последствия применения (или нет) правил в конкретных контекстах. Примеры отобраны из некоторых романов Фандоринского цикла Бориса Акунина и их переводов на польский язык.

Применяемая в русском языке транскрипция, учитывающая произношение, может привести к появлению труднопроизносимых, „не свойственных принимающему языку звуко- и буквосочетаний". Как утверждает Д.И. Ермолович, в результате „принцип фонетического подобия может быть в отдельных случаях подчинен принципу благозвучия". Одним из методов реализации этого принципа является метод эвфонической передачи. Он заключается в замене неблагозвучных буквосочетаний, возникших в результате применения практической транскрипции, на более благозвучные [Ермолович 2005: 139].

По мнению Д.И. Ермоловича, „в некоторых случаях метод эвфонической передачи оправдывается характером переводимого текста и учетом его адресата", но для его применения „необходимы серьезные основания и учет всех факторов, определяющих достижение цели коммуникации" [Ермолович 2005: 139]. Замечания исследователя касаются передачи имен собственных в русском языке, но они имеют общий характер. Поэтому в какой-то степени их можно отнести к польскому языку как принимающему определенное имя, тем более что переводчик встречается с единицей в русскоязычном облике.

В переводах анализируемых романов упомянутые имена собственные из т. н. третьей культуры появляются если не в неожиданном варианте записи, то в одной из возможных форм, ср. Шарль $\partial^{\prime} Э$ Вре [Т: 36] ${ }^{1}$ - Charles d'Evrait [G: 28], Шеймас Маклафлин [T: 32] - Seamus McLaughlin [G: 26]. Переводчик Туреикого гамбита руководствовался принципом отражения языковой принадлежности, но, как следует из приведенных примеров, он допускает некоторые изменения при возвращении к ори-

\footnotetext{
${ }^{1}$ Сокращения заглавий романов-источников даются в конце статьи.
} 
гинальной записи, т. е. к языку, из которого имя происходит, или выбирает один из потенциальных вариантов.

Плавную передачу подобного рода персоналий нарушает наличие алфавитного барьера и упомянутых различных норм введения иноязычных лексических элементов в русский и польский тексты. Традиционные способы передачи общеизвестны, однако русские правила, учитывающие фонетическое подобие, сопоставляемые в процессе русско-польского перевода с польским принципом оригинальной записи, значительно затрудняют установление родной (оригинальной) записи. Некоторые исследователи считают необходимость передачи элементов третьей культуры нарушением двуязычия переводчика, так как переводчики обучаются двум языкам, а другие языки находятся как бы вне их специальности [ср. Урбанэк 2004: 161].

Ситуация еще более усложняется, если единица выполняет в тексте дополнительные функции, т. е. кроме культурной специфики передает какие-нибудь семантические оттенки, подчеркивает характер высказывания, является частью интертекстуальной игры и т. п. Примером может послужить развитие в тексте приведенной выше фамилии d’Эвpe - d'Evrait.

В ходе повествования оказывается, что выступающая в романе и не вызывающая „подозрений” фамилия имеет довольно прозрачную и значащую внутреннюю форму, о чем свидетельствует экспликация в заключительных фрагментах текста. Очевидно, что переводчик вынужден приспособить запись для известных ему после ознакомления с романом заключительных решений. Хотя дело кажется несложным, приведенный ниже иллюстративный материал свидетельствует о существенных изменениях в области семантики, синтаксиса, а в результате - в последовательном ходе событий. Ср. оригинал с польским переводом:

Ну как же, - удивился Эраст Петрович. - Вы проявили такую неосторожность. Нельзя же до такой степени бравировать и недооценивать противника! Стоило мне первый раз увидеть вашу подпись в „Ревю паризьен” - d'Hevrais, и я сразу вспомнил, что наш главный оппонент Анвар-эфенди, по некоторым сведениям, родился в боснийском городке Xebpauc. D'Hevrais, „Xebpaucский" - это, согласитесь, слишком уж прозрачный псевдоним. Это, конечно, могло оказаться случайным совпадением, но так или иначе выглядело подозрительно 2 [Т: 247].

- No, jak to? Zdziwił się Erast Pietrowicz. - Pozostawił pan ślad w nazwisku, trochę je tylko zmieniając. Przedstawiając się, nie podał pan przecież pisowni,

2 Анализируемые в настоящей статье примеры (и множество других) подробнее рассматриваются в монографии автора Konteksty - Decyzje - Konsekwencje. Problemy przektadu, Wydawnictwo UKW, Bydgoszcz 2016. 
a ja myślałem, że pisze się: d’Hevrais. Kiedy więc usłyszałem, że nasz główny adwersarz, Anwar-efendi, urodził się prawdopodobnie w bośniackim miasteczku Hewrais, od razu to sobie skojarzyłem. D'Hevrais, a więc rodem stamtąd - taki pseudonim, zgodzi się pan, byłby całkiem przejrzysty. Nie wolno nie doceniać przeciwnika! Później okazało się, że pisownia jest inna, ale pierwsze wrażenie pozostało [G: 181].

В переводе приведенного фрагмента изменения семантического и хронологического характера привели к информационным сдвигам и, следовательно, к возникновению ошибочного впечатления, что Эраст Фандорин подозревал д'Эвре уже после первой информации об Анваре-эфенди и упоминании о встрече с д'Эвре, в то время как процесс дедукции был значительно более сложным. Дополнительная разница касается оценки прозрачности псевдонима: в оригинале Фандорин считает ассоциацию слишком очевидной, в польском же варианте она не является настолько явной, между прочим, из-за ссылки на произношение.

Различия между исходным фрагментом и его переводом можно комментировать с когнитивных позиций. Тексты составлены из таких же кусочков информации, но их грамматико-синтаксическая реализация ведет к существенным изменениям, связанным с механизмом профилирования. В когнитивной семантике Р. Лангакера профиль рассматривается как один из типов выделения. В рамках определенной сцены он является подвидом структуры, на котором фокусируется внимание, иначе - это то, что единица обозначает, или то, к чему она относится в концептуальной базе. Изменения касаются также хронологии событий и перспективы отражения события, что приводит к иному толкованию описываемой ситуации [ср. Langacker 2009: 99-119].

Следует также помнить о коннотативных аспектах передачи. В рамках определенной языковой системы наличие культурного отпечатка имени собственного воспринимается вполне естественно, как очевидная ассоциация. Зато в процессе межкультурной коммуникации оценка ценности и роли внутренней формы слова и решение о способах ее отражения вместе с культурными коннотациями в языке принимающей культуры принадлежит переводчику, потому что любое решение приводит к определенным последствиям. В качестве показателей культурной принадлежности могут быть использованы, например, вежливые адресативные формы, ср. monsieur (д’Эвре) или mister (McLaughlin).

Показатели подобного характера применяются также в процессе стилизации, служащей характеристике персонажа как иностранца, и для выражения отношения к некоему лицу. В романе Азазель, подытоживая неудачный визит Фандорина у леди Эстер, Бриллинг, желая проявить проницательность и одновременно отвлечь внимание от по- 
дозреваемой, подражает ее экзальтированному голосу и способу высказывания с английскими вставками. Ср.:

Дайте угадаю. Про мистера Kokorin миледи в жизни не слышала, про мисс Bezhetskaya тем паче, весть о завещании самоубийцы ее ужасно расстроила. Так? [A: 106].

Для того чтобы придать высказыванию сходство с языком фиктивной / вымышленной героини, в оригинале автор воспользовался оборотами мистер, миледи, мисс и записью фамилий с помощью русско-английской транскрипции в именительном падеже, независимо от грамматической структуры.

Польский переводчик не имел такой же возможности из-за правил, т. е. стандартной передачи антропонимов с помощью латинского алфавита. Ежи Чех использовал, аналогично как и в остальных фрагментах текста, транскрибированную запись фамилий и ввел их в текст согласно грамматическим правилам языка оригинала, отказавшись от задуманной автором стилизации, ср.:

Niech zgadnę. O mister Kokorinie milady nigdy nie słyszała, o miss Bieżeckiej tym bardziej, wiadomość o testamencie samobójcy wytrąciła ją z równowagi. Czy tak? [Az: 81].

Последовательностью переводческого решения, заключающегося в отказе от повторения русско-английской транскрипции, стало отсутствие эффекта иронического подражания, иначе говоря - потеря семантических и экспрессивных коннотаций. Внутренний смысл высказывания оказался ослабленным, хотя имелась возможность его усилить, что можно заметить в других местах Фандоринского цикла.

Можно выдвинуть тезис, что чуждость и связанные с ней трудности в восприятии имен собственных являются одной из причин сравнительно небольшого количества читателей русской литературы в Польше. В условиях глобализации и в связи с доминирующей ролью английского языка, английские слова, как и много других единиц, записываемых латинским алфавитом, воспринимаются более естественным образом, чем транскрибированные варианты, несмотря на близкое родство систем русского и польского языков. Такое положение не может оставаться без влияния на желание ознакомиться с произведениями из данного культурного круга, не говоря уже об экономико-политической обусловленности межгосударственных отношений.

Вопрос соответствующей записи всегда является сложным, но количество факторов, которые вынужден учесть переводчик, может увеличиваться или уменьшаться в зависимости от уровня знания определенного языка и связанной с ним культуры носителями языка перевода.

Иллюстративным материалом могут здесь послужить фрагменты Черного города и его польского варианта Czarne miasto. Действие романа 
происходит в Баку с его многокультурным населением. В городе живут турки, татары, армяне, а также арабы, грузины, русские и т. д.; в результате не удивляет наличие имен и фамилий персонажей, принадлежащих к разным культурным кругам, находящимся вне намного лучше известного читателям западноевропейского пространства. Многокультурное влияние находит языковое отражение в антропонимической лексике оригинала, заметное в следующих записях: Mecpon Kapaneтович Арташесов [Ч: 109], Муса Джабаров [Ч: 110], Гаджи-ага Шамсиев [Ч: 110], Саадат Валидбекова [Ч: 204]. Единицы передаются переводчицей (А. Окуневской-Стронкой) с помощью практической транскрипции, ср. Miesrop Karapietowicz Artaszesow [CM: 111], Musa Dżabarow [CM: 112], Hadżi-aga Szamsijew [CM: 112], Saadat Walidbekowa [CM: 211].

В упомянутом романе встречаются также значимые / значащие 3 имена, которыми временно именуется Эраст Фандорин, введенные Б. Акуниным в текст оригинала согласно правилам практической транскрипции, учитывающей в некой степени произношение: Агбаш oraz Юмрубаш, ср.:

Не буду тебя звать „Агбаш”, - сказал Гасым. - Будешь Юмрубаш, Круглый Голова [Ч: 155].

По отношению к выделенным единицам, а также некоторым единичным словам и фразам, которые произносит товарищ главного героя Гасым (Наsym), автор перевода воспользовалась, согласно теоретическим рекомендациям, другой техникой, т.е. старалась вернуться к оригинальной записи в исходном языке. В данном случае это азербайджанский язык ${ }^{4}$, алфавит которого подлежал многим изменениям на протяжении предыдущего столетия. Переводчица Черного города приняла в конце концов решение о применении латиницы, которая в 1992 г. вновь заменила так называемую азербайджанскую кириллицу5 ${ }^{5}$ В латинском варианте записи содержатся буквы, принадлежащие в современную эпоху также турецкому алфавиту, например ş, что повлияло на дальнейшие решения переводчика. В результате такого приема читатель перевода получает упомянутый фрагмент в следующем виде:

3 Термином значимые имена пользуется В.С. Виноградов. В дальнейшем будет применяться термин значащие имена вслед за Н.К. Гарбовским и Д.И. Ермоловичем.

4 Азербайджанский язык является одним из языков юго-западной ветви тюркских языков. На протяжении XX века азербайджанская письменность менялась четырежды. В настоящее время азербайджанцы пользуются тремя видами письма: арабицей - в Иране, латиницей - в Азербайджане и кириллицей - в Дагестане (России), ср. электронный ресурс: https://ru.wikipedia.org/wiki/\% (28.12.2015).

${ }^{5}$ Cр. электронный ресурс: http://www.szkolnictwo.pl/szukaj,J\%C4\%99zyk_azerski (28.12.2015). 
Nie będę cię nazywać Akbaş - powiedział Hasym. Będziesz Yumrubaş, Okrągły Głowa [CM: 160].

С точки зрения читателя действительно могло бы показаться, что примененная запись имеет оригинальный характер, однако на самом деле переводчик обратился к турецкому, а не к азербайджанскому языку. Доказательством может послужить передача значения 'белый как снег', которое в переводе передается с помощью турецкого слова $a k$ вместо азербайджанского $a \breve{g}$, на которое опирается русский вариант имени.

И в этот момент следует задать несколько вопросов. Готов ли польский читатель на столь сильное увеличение чуждости? Стоило ли модифицировать переводческую технику, которая была применена по отношению к другим единицам из т. н. третьей культуры? Действительно ли желание сохранить и передать в процессе перевода культурную специфику важнее гармонии восприятия? Может быть, следовало принять во внимание возможности восприятия польского получателя, учитывая более широкий культурный контекст. Ведь, собственно говоря, невозможно говорить о каких-нибудь фоновых знаниях польских читателей относительно азербайджанского или турецкого языков, а представленная запись затрудняет польскому реципиенту даже прочтение имен и фамилий и напрасно сосредоточивает его внимание на записи, что совсем не было целью автора оригинала. Кроме того, запись в польском варианте ссылается на турецкий язык, а не на азербайджанский. Следовательно, точное направление ассоциаций не сохранилось, хотя надо констатировать, что из-за недостаточных общих знаний это осталось совсем незаметным для читателей.

Надо также подчеркнуть, что ощущение усиленной чуждости появилось бы также тогда, когда, как в случае других антропонимов, была бы применена транскрипция, опирающаяся на польский алфавит, например Agbasz, Jumrubasz, потому что с точки зрения польского читателя так или иначе эти единицы были бы оценены как не относящиеся ни к культуре оригинала, ни перевода. С одной стороны, кажется, что использование дополнительно экзотирующего текст приема трудно считать желательным, но, с другой стороны, можно посмотреть на результат перевода с точки зрения индивидуального решения переводчика, отдающего себе отчет в его последствиях. Это один из потенциальных вариантов, более того - обоснованных вариантов. Другой переводчик мог бы принять другое решение, хотя бы из-за отсутствия стандартов передачи с упомянутого исходного языка на польский язык.

Следует также отметить, что не всегда значащие имена вызывают трудности в процессе перевода. Доказательством может послужить 
фрагмент с подпольными кличками представителей преступного мира в Баку, ср.:

При этом всякой пернатой нечисти в городе было достаточно: армянский бандит Черный Ястреб, лезгинский бандит Белый Сокол, русский налетчик просто Сокол, тюркский головорез Лешиейэн, то есть Стервятник, а вот про Дятла ничего разузнать не удалось [...] [Ч: 210].

В приведенном контексте перевод сводится к применению словарного эквивалента. Не мешает даже то, что мотивировка называния играет существенную роль, потому что важной является черта, ассоциирующаяся в сознании реципиентов с определенной птицей, а не внутренняя форма самого названия, ср.:

Jak na złość wszelakiego skrzydlatego diabelstwa było w mieście w bród: ormiański bandyta Czarny Jastrzą, lezgiński bandyta Biaty Sokót, rosyjski rabuś po prostu Sokót, turkijski zbój Leşyiyen, czyli Sęp. Natomiast na temat Dzięcioła nie udało się dowiedzieć niczego [...] [CM: 217].

Исключением является запись псевдонима тюркского убийцы. Переводчица признала уместным сохранить намек на культурную принадлежность персонажа, применяя турецкий алфавит, хотя, как указывалось выше, соблюдение отличающихся друг от друга общих правил передачи приводит к разным результатам, т. е. к разному восприятию единиц в русском и польском языках. Русская практическая транскрипция, учитывающая произношение, позволяет в меру свободно прочитать слово Лешиейэн, в то время как оригинальная турецкая запись в польском языковом окружении расстраивает восприятие текста. Проблемы обоснованности применения такого приема мы коснулись при рассмотрении предыдущих примеров, хотя исходным был тогда азербайджанский язык.

Следует еще обратить внимание на то, что псевдоним появляется вместе с соответствием, в котором эксплицировано значение чужого слова, к тому же непонятная запись не играет такой существенной роли, как в вышеописанной ситуации. Поэтому внимание на единице не сосредоточивается, можно даже полагать, что она в таком языковом окружении становится незаметной или еле заметной при чтении.

Подытоживая вышесказанное, следует подчеркнуть, что перевод персоналий ни в коем случае не должен рассматриваться как автоматический процесс передачи. В зависимости от функции, выполняемой антропонимической лексикой в тексте, переводческие решения должны быть ориентированы в большей степени на форму (и, например, ее благозвучность) или на значение (как в случае значащих имен), причем в обоих случаях доминирующую роль играют потенциальные ассо- 
циации, которые могут возникнуть у читателей перевода. Такой подход неизбежно ведет к индивидуальному подходу, поскольку связан с многоуровневым и многоаспектым анализом статуса единицы как в тексте оригинала, так и в тексте перевода.

\section{Библиография}

А л е к с е е в а И.С., (2008), Текст и перевод. Вопросы теории, „Международные отношения", Москва.

В и н о г р а д о в В.В., (1977), Об основных типах фразеологических единии в русском языке, Издательство „Наука”, Москва.

В и н о г р а д о в В.С., (2006), Перевод. Общие и лексические вопросы, Издательство „Наука”, Москва.

В л а х о в С.И., Ф л о р и н С.П., (1980), Непереводимое в переводе, „Международные отношения", Москва.

Г а р б о в с к и й Н.К., (2007), Теория перевода, Издательство Московского университета, Москва.

Е р м о л о в и ч Д.И., (2005), Имена собственные: Теория и практика межъязыковой передачи, Издательство „Р. ВАЛЕНТ”, Москва.

Jó ź wi a k J., (2016), Konteksty - Decyzje - Konsekwencje. Problemy przekładu, Wydawnictwo UKW, Bydgoszcz.

L a $\mathrm{n}$ g a c k e r R.W., (2009), Gramatyka kognitywna. Wprowadzenie, tłum. E. Tabakowska, M. Buchta, H. Kardela i in., TAiWPN UNIVERSITAS, Kraków.

L e w i c k i R., (2000), Obcość w odbiorze przekładu, Wydawnictwo UMCS, Lublin.

U r b a n e k D., (2004), Pęknięte lustro. Tendencje w teorii i praktyce przekładu na tle myśli humanistycznej, Wydawnictwo Trio, Instytut Rusycystyki Uniwersytetu Warszawskiego, Warszawa.

А к у н и н Б., (1998/2008), Азазель, „Захаров”, Москва.

А к у н и н Б., (1999/2007), Турецкий гамбит, „Захаров”, Москва.

А к у н и н Б., (2012/2014), Черный город, „Захаров", Москва.

A k u n i n B., (2003), Azazel, przeł. J. Czech, Świat Książki, Warszawa.

A k u n i n B., (2003), Gambit turecki, przeł. J. Czech, Świat Książki, Warszawa.

A k u n i n B., (2014), Czarne miasto, przeł. A. Okuniewska-Stronka, Świat Książki, Warszawa.

Skróty tytułów powieści źródłowych

$\begin{array}{lll}\text { Азазель } & - & {[\mathrm{A}]} \\ \text { Azazel } & - & {[\mathrm{Az}]} \\ \text { Tурецкий гамбит } & - & {[\mathrm{T}]} \\ \text { Gатьіt turecki } & - & {[\mathrm{G}]} \\ \text { Черный город } & - & {[\mathrm{Ч}]} \\ \text { Czатпе miasto } & - & {[\mathrm{CM}]}\end{array}$


